\title{
Emerging Roles of Interleukin-33-responsive Kidney Group 2 Innate Lymphoid Cells in Acute Kidney Injury
}

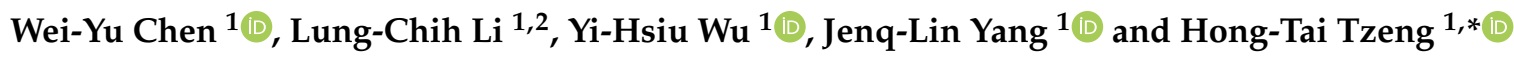 \\ 1 Institute for Translational Research in Biomedicine, Kaohsiung Chang Gung Memorial Hospital, \\ Kaohsiung 83301, Taiwan; wychen624@cgmh.org.tw (W.-Y.C.); r5239@cgmh.org.tw (L.-C.L.); \\ martinwu19860626@gmail.com (Y.-H.W.); jyang@cgmh.org.tw (J.-L.Y.) \\ 2 Division of Nephrology, Department of Internal Medicine, \\ Kaohsiung Chang Gung Memorial Hospital and Chang Gung University College of Medicine, \\ Kaohsiung 83301, Taiwan \\ * Correspondence: htay11@cgmh.org.tw; Tel.: +886-7-7317123 (ext. 8595)
}

Received: 30 December 2019; Accepted: 22 February 2020; Published: 24 February 2020

\begin{abstract}
Interleukin (IL)-33, a member of the IL-1 family of cytokines, is involved in innate and adaptive immune responses. IL-33 triggers pleiotropic immune functions in multiple types of immune cells, which express the IL-33 receptor, ST2. Recent studies have revealed the potential applications of IL-33 for treating acute kidney injury in preclinical animal models. However, IL-33 and IL-33-responding immune cells are reported to exhibit both detrimental and beneficial roles. The IL-33-mediated immunomodulatory functions have been investigated using loss-of-function approaches, such as IL33-deficient mice, IL-33 antagonists, or administration of exogenous IL-33 recombinant protein. This review will discuss the key findings on IL-33-mediated activation of kidney resident group 2 innate lymphoid cells (ILC2s) and summarize the current understanding of the differential functions of endogenous IL-33 and exogenous IL-33 and their potential implications in treating acute kidney injury.
\end{abstract}

Keywords: interleukin-33; acute kidney injury; group 2 innate lymphoid cells

\section{Introduction}

Interleukin (IL)-33, a nuclear cytokine belonging to the IL-1 family, has pleiotropic immunomodulatory functions and is involved in various inflammatory diseases [1]. IL-33 is expressed in various cell types, such as endothelial cells, fibroblasts, epithelial cells, and immune cells [1,2]. In humans, IL-33 functions as a tissue-derived nuclear alarmin [3,4] and is constitutively expressed in the epithelial barrier and endothelial barrier tissues [3,5]. In steady state, IL-33 is quenched within the cell through interaction with histones [6]. During apoptosis, intracellular IL-33 is inactivated by caspases like caspase- 3 and caspase-7, making them immunologically silent. Unlike IL-1 $\beta$ and IL-18, caspase- 1 mediates the inactivation of IL-33 by cleavage of its central domain [7]. Under tissue damage, IL-33 is released in its full length, which is the active form [1]. Moreover, some inflammatory proteases like tryptase from mast cells and cathepsin $\mathrm{G}$ and elastase from neutrophils further boost the activity of IL-33 [8,9].

The receptor complex for IL-33 comprises the ST2 subunit, which is encoded by the IL1RL1 gene, and IL-1 receptor accessory protein (IL-1RAcP), a coreceptor [3,10]. The ST2-IL-1RAcP heterodimeric receptor is formed after binding of IL-33 ligand [11]. Both IL-1RAcP and ST2 contain toll-interleukin receptor (TIR) domain, recruiting myeloid differentiation primary response 88 (MyD88), IL-1 receptor-associated kinase-1 (IRAK-1) and TNF receptor-associated Factor 6 (TRAF6). The protein complex transmits activation 
signal through p38, c-Jun N-terminal kinases (JNK), and nuclear factor kappa B (NF- $\mathrm{kB}$ ) pathways [12]. Also, a TRAF6-independent mechanism of extracellular signal-regulated kinase (ERK) activation has been demonstrated [13]. These pathways largely overlap with Toll-like receptors (TLR), IL-1 and IL-18 receptor signaling, and a ST2-specific mechanism is proposed to achieve Th2-biased gene expression [14]. This idea may be illuminated by a recent study, which suggests the activity of peptidyl-prolyl cis-trans isomerase NIMA-interacting 1 (PIN1) inducing isomerization and nuclear translocation of IRAK-M as well as triggering Th2-gene expression in dendritic cells [15]. Conversely, single Ig IL-1-related receptor (SIGIRR) is known to suppress type-2 response through TIR domain interaction with ST2 protein [16].

Recently, several studies have suggested that IL-33 is involved in the pathogenesis of kidney diseases and the associated tissue reparative responses $[17,18]$. For example, IL-33 level had increased in unilateral urinary obstruction (UUO) model in mice [19]. Also, a cisplatin-induced kidney injury results in increased serum levels of IL-33 [20]. Furthermore, IL-33 has been shown to be upregulated in kidney and linked to ferroptosis [21]. The elevation of IL-33 or ST2 levels in the urine has also been investigated in renal transplant [22]. Despite multiple kidney injury models resulting in the upregulation and release of IL-33, the correlation of kidney injury and clinical outcome is not unified, which may be due to the diverse pathogenic effects of IL-33 and limitations on the tools to detect IL-33 level in serum and urine samples (reviewed in Chen et al.) [18].

Acute kidney injury (AKI) is a common complication among hospitalized patients [23]. AKI is characterized by acute deterioration of kidney function and disruption of electrolyte and fluid homeostasis, which occur within a few hours or days. AKI is associated with increased long-term risks of poor clinical outcomes, including chronic kidney disease (CKD), cardiovascular disease, and mortality $[23,24]$. Currently, the commonly used biomarker of renal function is serum creatinine (SCr) [25]. Creatinine is a waste product in the blood that is generated from muscle activity. Creatinine is normally removed from the blood by the kidneys. However, the creatinine levels increase with the deterioration of kidney function. AKI is characterized by elevated $\mathrm{SCr}$ levels within 7 days or by a sustained reduction in urine output over $6 \mathrm{~h}$ [25]. However, Scr is not a sensitive marker for early AKI event, and, therefore, the development of more sensitive, accurate, and cost-effective biomarker assays for clinical AKI assessment other than Scr analysis is crucial [26]. In addition to SCr, several urine biomarkers have emerged as more sensitive indicators for early detection of AKI, such as urine levels of kidney injury molecule-1 (KIM-1), neutrophil gelatinase-associated lipocalin (NGAL), activin A, and insulin-like growth factor-binding protein 7 (IGFBP-7) [27-30]. Urine Biomarker [(Tissue inhibitor of metalloproteinases 2) TIMP-2] $\times$ [IGFBP-7] level has also been proposed as a promising indicator for clinical AKI risk assessment [31].

One of the major challenges for AKI treatment is the heterogeneity of the disease. The pathophysiology of AKI varies according to the different conditions associated with its development [32]. AKI could be induced by drugs, renal toxins, sepsis, glomerulonephritis, or acute ischemic reperfusion [32]. Traditionally, maintenance of adequate renal vascular perfusion through volume and hemodynamic management remains the major medical treatment for AKI, as well as avoiding nephrotoxins and drugs associated with kidney injury [33]. Renal replacement therapy can be implemented while awaiting clinical signs of renal function recovery [32]. However, an effective therapy for preventing acute kidney injury, apart from supportive management, remains a largely unmet medical need.

Following acute kidney injury, an initial phase involving cell damage or cell death occurs in accordance with the specific nature of the insults. This phase lasts from minutes to hours and involves epithelial, endothelial, and other renal parenchymal cells in certain specific or even all zones of the kidneys [34]. At this stage, the damaged tissue/cells release a broad range of danger signals for initiating an acute inflammatory response. Following the primary insult, a phase of tissue inflammation is initiated and mediated predominantly by tissue-resident and infiltrating immune cells including neutrophils and macrophages [35]. The recruited immune cells promote the clearance of dead cell debris and trigger anti-inflammation responses by secreting anti-inflammatory factors to 
promote inflammation resolution and tissue repair [35]. Renal peritubular fibroblasts are activated and promote extracellular matrix production for tissue repair [36]. However, maladaptive repair or excessive interstitial myofibroblast activation may result in excessive extracellular matrix (ECM) deposition and worsen renal function recovery [37]. The tissue reparative process could last for long periods (days to weeks) after acute tissue damage depending on the type of injury insults, reparative capability, efficiency of dead cell clearance by phagocytes, and resolution of inflammatory responses [38]. In a clinical study, more than $80 \%$ of the patients who experienced an AKI episode recovered their renal function within the first week, while approximately $17 \%$ recovered after more than a week [39]. The mechanism underlying successful and maladaptive tissue repair, as well as excessive fibrosis remains to be completely elucidated.

To better understand the underlying molecular mechanism and the contribution of immune cells in the progression of AKI, several animal models of AKI have been established. The most common mouse models of AKI that have been generated include ischemia-reperfusion injury (IRI), chemical-induced injury (doxorubicin or cisplatin), and UUO [40-42]. These animal models have helped improve our understanding of tissue responses to acute kidney insults and the involvement of different types of immune cells or cytokines in the inflammatory and reparative phases [35]. However, the experimental design for assessing the outcome may affect the interpretation of the results. Therefore, there is a need to comprehensively analyze the dynamic changes in tissue reparative responses, immune cell profiles, fibrosis markers, and soluble serum markers for evaluating kidney injury and to gain an in-depth understanding of the detailed mechanism underlying the regulation of inflammatory process at different phases of disease onset.

Several studies have demonstrated that both innate and adaptive immune responses contribute to tissue inflammation post-kidney injury [43]. However, the mechanism underlying the regulation of tissue inflammation and inflammation resolution is unclear. Cytokines are reported to be involved in the progression of renal fibrosis and tissue damage [44]. IL-33 is reported to promote type 2 immune responses and allergic diseases in mucosal tissues, such as lung, intestine, and skin [45]. However, IL-33 also promotes anti-inflammatory responses to suppress the inflammation via alternatively activated macrophages (AAMs), myeloid-derived suppressive cells (MDSCs), and regulatory T-cells (Tregs) [46,47]. Recent studies have also demonstrated that IL-33-mediated immune responses are involved in renal protection using mouse AKI models [48-51]. The growth factors, such as amphiregulin (AREG) derived from IL-33-responsive group 2 innate lymphoid cells (ILC2s) or Tregs, are reported to promote epithelium regeneration after tissue injury [52]. In addition to the renal protective functions in AKI models, recent studies have reported the detrimental effects of IL-33, which involve promoting renal fibrosis [53-55]. This review summarizes the current findings on IL-33-mediated immune responses in kidney injury, repair, and fibrosis.

\section{Roles of IL-33-Mediated ILC2 Activation in the Kidney}

Several studies have reported the pathological roles of IL-33 in renal IRI [53], cisplatin-induced AKI [20], and ovalbumin-induced nephrotoxicity models [56]. Additionally, some recent studies have demonstrated that IL-33-mediated immune responses contribute to renal protection in the mouse AKI models [48-51]. The IL-33/ST2 signaling pathway may function as a double-edged sword and is involved in both the pathological and tissue reparative processes by affecting various cell types at different phases of disease progression [18]. The recent findings on the characterization of kidney IL-33-responsive immune cells, especially ILC2s, in kidney injury are discussed below.

\subsection{Characterization of IL-33-Responsive Kidney ILC2s}

The tissue ILC subsets are largely characterized by flow cytometric analysis of the cell surface markers, nuclear transcription factors, or intracellular cytokine expression [57]. Riedel et al. analyzed the distribution of ILC subsets in the human and mouse kidneys [48]. The flow cytometry analysis revealed that the total ILCs (Lin-CD127+CD161+) comprise CRTH2+ ILC2s, NKp44+, 
and NKp44-CRTH2-CD117+ ILC3s, while a small population of CRTH2-CD117-NKp44-ILC1s reside in the normal human kidney [48]. The study also identified that the normal mouse kidney has Lin-GATA3+ ILC2s and small populations of ROR $\gamma \mathrm{t}+$ ILC3s and Tbet+ILC1s. In the normal mouse kidney, ILC2s constitute $80 \%$ of total ILC subsets [48]. Upon IL-33 treatment ( $0.4 \mu \mathrm{g}$ per day for 4 consecutive days, intraperitoneal (i.p.)), the kidney ILC2s expand and sustain for up to 13 weeks. The renal ILC2s express the IL-33 receptor, ST2, and CD25 in the healthy human and mouse kidneys [48]. The tissue localization was further validated by immunofluorescent staining using suitable antibodies for different surface or nuclear antigens [48]. The immunofluorescent staining analysis revealed that the kidney ILC2s are localized in the glomerular and tubulointerstitial compartment around the peritubular capillaries [48]. Cao et al. also analyzed the distribution of kidney ILC2s using flow cytometry, which revealed that IRI alone did not alter the number of kidney ILC2 and that the treatment with exogenous IL-33 enhances the ILC2 populations [49].

Our previous study had analyzed the ST2+ immune cell profile in the unilateral urinary obstruction (UUO) mouse model [58]. The study reported that kidney ILC2s (CD45+Lin-Thy1.2+GATA3+) constitute the major population (approximately 70\%) among the total ILC subsets in the normal and injured kidneys [58]. In addition to kidney ILC2s, other ST2-expressing immune populations were also identified. Among the ST2+ cells, the CD45- non-leukocytes, neutrophils, macrophages, T/ILCs, and monocytes comprised $34.8 \%, 22.3 \%, 23.1 \%, 16.2 \%$, and 3.6\%, respectively [58]. Compared with the nonobstructed kidneys, the UUO kidneys exhibited a 30-fold increase in the number and a 4.6-fold increase in the percentage of ST2+ neutrophils [58]. These results indicate that there is increased infiltration and expansion of ST2+ innate immune cells in the kidney following obstructive injury.

Cameron et al. comparatively analyzed the phenotypes of kidney and lung ILC2s using flow cytometry analyses [59]. The analyses revealed that the kidney ILC2s exhibited lower CD25 expression, consistent expression of inducible T cell costimulator (ICOS) and killer cell lectin like receptor G1 (KLRG1), and upregulated IL-5 expression when compared with the lung ILC2s [59]. The study used the Rosa-tdtomato lineage tracker to label the IL-5-expressing cells and reported that the kidney ILC2s are localized around the vasculature under homeostatic conditions [59]. Additionally, the renal ILC2s were reported to be the major IL-5-producing cells in the kidney [59]. Intriguingly, reduction, deficiency, or depletion of ILC2s does not alter the severity of kidney injury in mice following IRI. This suggested that other type 2 immune responses may compensate for the absence of ILC2s [59]. In humans, the lack of ILCs might be compensated by other T-cell and B-cell preserved functions [60]. The ILC2s present in the human kidney [48] may be a potential therapeutic target for treating kidney diseases. However, the role of activated kidney-resident ILC2s in the renal protective response in humans is unclear.

An increasing body of evidence revealed the presence of ILC2s residing in the healthy kidneys of humans and mice (Table 1). The regulation of ILC2 expansion by exogenous IL-33 may elicit the renal protective responses in mouse AKI models (Table 2). IL-33 has been shown to promote the egress of bone marrow ILC2s [61]. Since exogenous IL-33 activated systemic responses, it is not restricted in activation of kidney ILC2s. However, it is not clear whether IL-33-promoted ILC2 activation in other organs contributes to the renal protective functions via increasing the systemic serum factors. Also, it is not clear whether the IL-33-activated bone marrow or spleen ILC2s migrate and accumulate in the injured kidneys. The precise pathophysiological functions of the kidney-resident ILC2s in homeostasis and disease conditions remain largely unknown. 
Table 1. Characterization of kidney group 2 innate lymphoid cells (ILC2s).

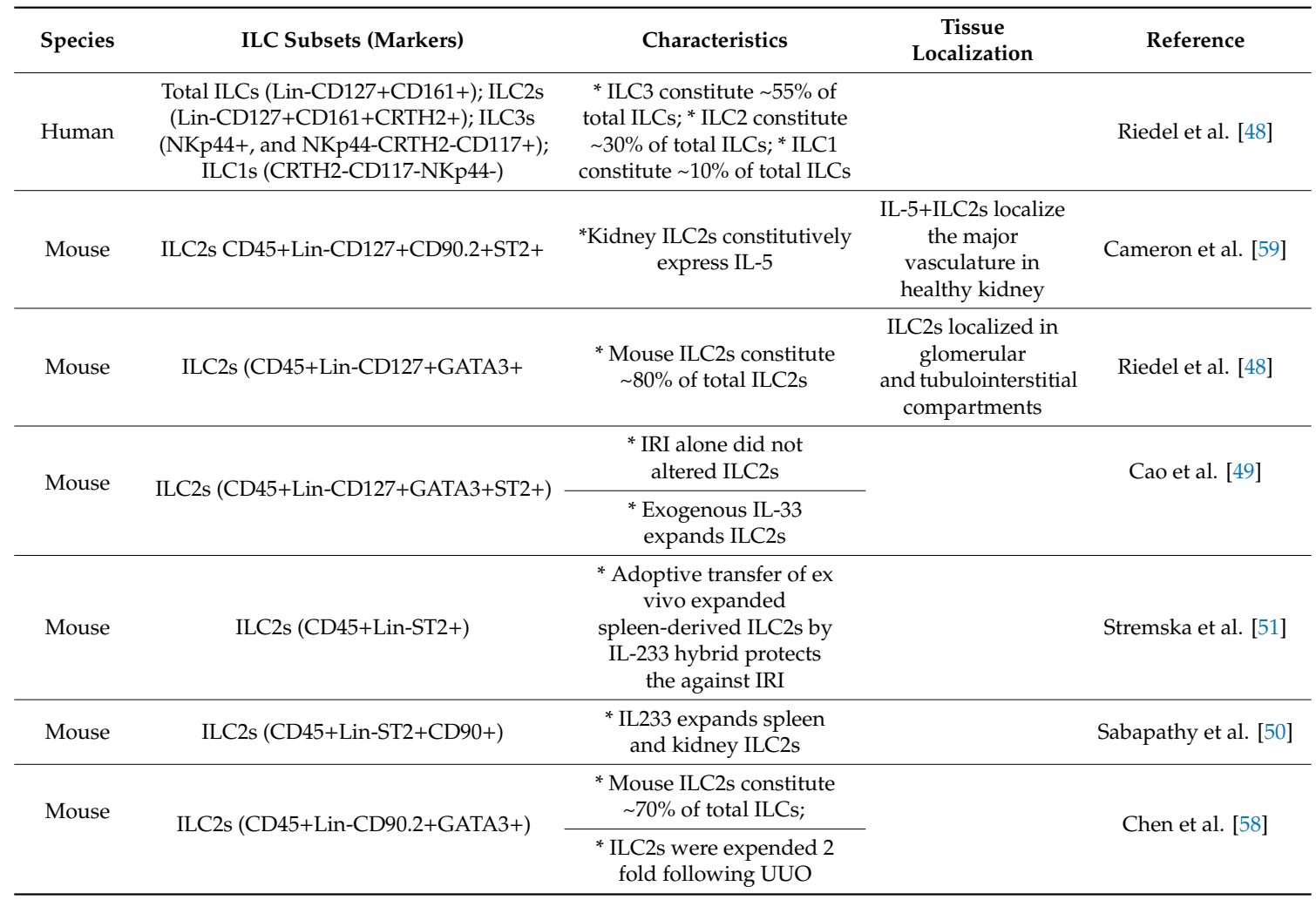

ILC, innate lymphoid cells; CRTH2, chemoattractant receptor-homologous molecule expressed on TH2 cells; Lin, lineage, GATA3, GATA binding protein 3; IRI, ischemia-reperfusion injury.

Table 2. Effects of endogenous and exogenous IL-33 in AKI models.

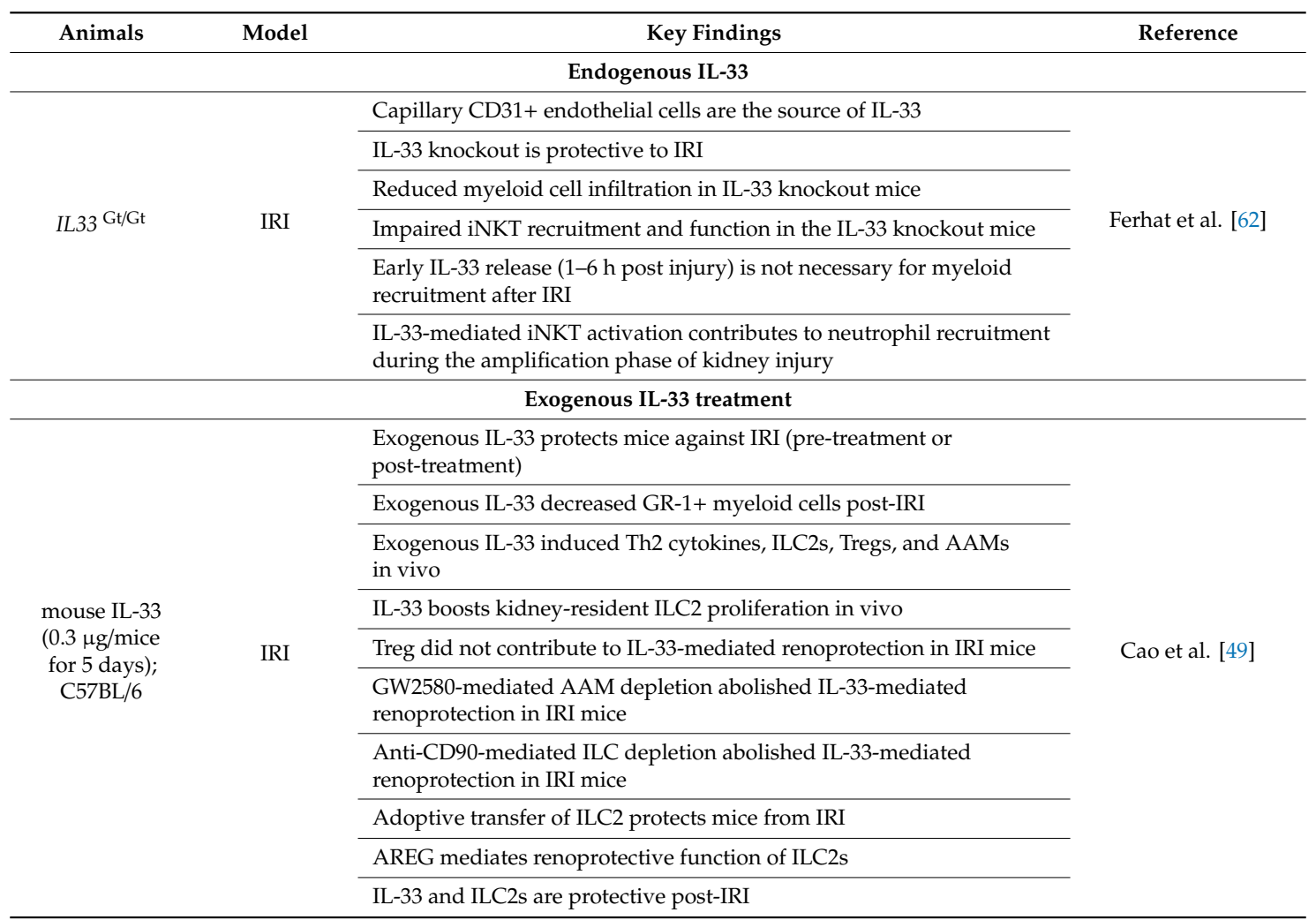


Table 2. Cont.

\begin{tabular}{|c|c|c|c|}
\hline Animals & Model & Key Findings & Reference \\
\hline \multicolumn{4}{|c|}{ Exogenous IL-33 treatment } \\
\hline \multirow{3}{*}{$\begin{array}{l}\text { mouse IL233 } \\
\text { (66 pmol /mice } \\
\text { for } 5 \text { days); } \\
\text { C57BL/6J } \\
\text { and Balb/cJ }\end{array}$} & \multirow{3}{*}{$\begin{array}{c}\text { IRI } \\
\text { Doxorubicin } \\
\text { Cisplatin }\end{array}$} & Exogenous IL-2 combined with IL-33 (IL233) is protective post-IRI & \multirow{3}{*}{$\begin{array}{l}\text { Stremska et al. [51]; } \\
\text { Sabapathy et al. [50] }\end{array}$} \\
\hline & & $\begin{array}{l}\text { IL233 promotes the expansion of ILC2s and Tregs, which is required for } \\
\text { the renal protective functions }\end{array}$ & \\
\hline & & $\begin{array}{l}\text { IL233 is renal protective in IRI-, cisplatin-, and doxorubicin-induced } \\
\text { nephrotoxicity }\end{array}$ & \\
\hline \multirow{2}{*}{ mouse IL-33 } & \multirow{2}{*}{ IRI } & Exogenous IL-33 promotes IRI-induced fibrosis & \multirow{2}{*}{ Liang et al. [53] } \\
\hline & & sST2 attenuates IRI-induced renal injury and fibrosis & \\
\hline \multirow{4}{*}{$\begin{array}{c}\text { mouse IL-33 } \\
\text { (0.4 } \mu \mathrm{g} / \mathrm{mice} \\
\text { for } 4 \text { days); } \\
\text { C57BL/6 } \\
\text { and Balb/c }\end{array}$} & \multirow{4}{*}{$\begin{array}{l}\text { Adriamycin } \\
\text { (Doxorubicin) }\end{array}$} & ST2+ILC2s are the major ILC2 population in human and mouse kidneys & \multirow{4}{*}{ Riedel et al. [48] } \\
\hline & & Exogenous IL-33 induces sustained ILC2 expansion in the kidneys & \\
\hline & & Exogenous IL-33 ameliorates Adrimycin-induced kidney injury & \\
\hline & & Eosinophils are required for IL-33-mediated tissue protection & \\
\hline
\end{tabular}

AKI, acute kidney injury; IRI, ischemia-reperfusion injury; ILC2, group 2 innate lymphoid cells, AAM, alternative activated macrophages; iNKT, invariant nature killer T-cells; sST2, soluble ST2.

\subsection{Recent Findings on Exogenous IL-33-Mediated ILC2s Activation in Kidney Injury Models}

In addition to the pro-inflammatory function, IL-33 enhances pulmonary tissue repair responses via ILC2s [63]. Recent studies have also revealed that IL-33-mediated activation of ILC2 cells, Tregs, and AAMs may have protective roles in renal injury. In the adriamycin-induced glomerulosclerosis model, treatment with exogenous IL-33 results in sustained expansion of ST2 ${ }^{+}$ILC2, which ameliorates the renal injury through eosinophils [48]. Huang et al. demonstrated that IL-25-responsive ILC2 and type 2 multipotent progenitor (MPPtype2) cells promoted macrophage polarization toward the M2 phenotype in the kidney and prevented acute renal IRI [64]. Cao et al. demonstrated that treatment with exogenous IL-33 protects the mice against IRI (pre-treatment or post-treatment). Treatment with exogenous IL-33 decreased the number of GR-1+ myeloid cells post-IRI and induced Th2 cytokines, ILC2s, Tregs, and AAMs in vivo. Interestingly, Cao et al. reported that Treg did not contribute to the IL-33-mediated renoprotection in IRI mice. GW2580-mediated AAM depletion or anti-CD90-mediated ILC depletion abolished the IL-33-mediated renoprotection in IRI mice [49]. Adoptive transfer of ILC2 protects the mice from IRI, which is mediated by AREG [49]. These results suggest that exogenous IL-33-mediated ILC2 activation reduces tissue inflammation and promotes tissue repair following IRI.

Recently, Sharma et al. combined IL-2 and IL-33 for fine-tuning the immunomodulatory effects of IL-33 on Tregs and ILC2s [51]. The hybrid IL-2-IL-33 (IL233) fusion protein exhibited promising therapeutic efficacy in various mouse models of kidney injuries, including IRI [51], doxorubicin-induced nephrotoxicity [50], lupus nephritis [65], and diabetic nephropathy [66]. These studies indicated that the IL233 fusion protein could be a novel immunomodulatory cytokine that regulates multiple nephropathic factors with potential renoprotective applications. Whether IL233 could be applied to other disease models could be interesting and require further investigation. These recent studies suggest that exogenous IL-33-mediated ILC2 activation has a role in protection against AKI in mice.

Although the IL-33 protein levels are upregulated in the kidneys after AKI, the kidney-resident ILC2s are not accumulated or expanded unless exogenous IL-33 was systemically administered [48-51]. This potentially implied that the endogenous IL-33 may not be sufficient to elicit the expansion of kidney ILC2s. However, the local elevation in the IL-33 protein levels may be sufficient to mediate the immunomodulatory function, which promotes neutrophil infiltration and amplifies the tissue innate inflammation during the acute inflammatory phase of AKI. The exogenous IL-33-mediated expansion of ILC2s and Tregs may skew the tissue immune microenvironment toward the tissue reparative responses that favor inflammation resolution and regeneration. We summarized the key findings of recent studies on the effect of endogenous and exogenous IL-33 in AKI models (Table 2). 
In contrast to the short-term administration of IL-33, the prolonged systemic IL-33/ST2 signaling activation might be detrimental after the recovery of damaged tissue. IL-33-mediated immunosuppression is reported to be associated with sepsis-induced immunosuppression [67]. The role of exogenous IL-33-induced immunosuppression in inducing global immunosuppression at the later stage of tissue recovery in the IRI models remains unclear and must be elucidated for optimizing the timing and duration of IL-33-based therapy.

\section{Roles of Endogenous IL-33 Versus Exogenous IL-33 in Kidney Injury, Repair, and Fibrosis}

Genetically modified mice lacking endogenous IL-33 or its receptor (ST2) have been used for the loss-of-function study to examine the role of IL-33/ST2 signaling in the pathogenesis of AKI. Ferhat et al. demonstrated that endogenous IL-33 contributes to the recruitment of myeloid cells upon acute IRI using IL33-deficient mice [62]. IL-33 is constitutively expressed on blood vessels, especially peritubular and periglomerular endothelial cells $[20,62,68]$. Ferhat et al. also demonstrated that endogenous IL-33 is not required for early recruitment of myeloid cells post-IRI (1-6 h) but is required for the amplification of neutrophil-mediated inflammatory response via invariant natural killer T-cell (iNKT) [62]. Based on these results, Ferhat et al. concluded that endogenous IL-33 functions as a tissue alarmin and contributes to kidney IRI via IL-33-mediated iNKT activation and enhances neutrophil recruitment following AKI [62].

Akcay et al. revealed that treatment with high-dose exogenous IL-33 $(1 \mu \mathrm{g}$, twice a day on days 1,2, and 3 after cisplatin administration, i.p. injection) exacerbates cisplatin-induced AKI via CD4 T-cells/CXCL1 axis in the mouse model [20]. Administration of soluble ST2 (sST2; $100 \mu \mathrm{g} /$ day, on days 1, 2, and 3 of cisplatin administration) decreased the levels of $\mathrm{SCr}$, acute tubular necrosis, and tubular apoptosis [20]. The dose of IL-33 used in this study was higher than that used in other recent studies [48-51]. It is not clear if the detrimental effect of exogenous IL-33 observed in this study resulted from the excessive immune response elicited by IL-33. A recent study by Edelstein and colleagues reported that IL33 deficiency does not protect against cisplatin-induced AKI in mice with cancer [69]. In contrast to their earlier study that used acute high-dose cisplatin, this study used four weeks low-dose cisplatin to induce AKI. The effect of IL33 deficiency at the early time point (within one day post-cisplatin administration) was not analyzed. Hence, it is currently unknown whether the endogenous IL-33 contributes only to early inflammatory phase and is dispensable for the progression of sustained renal injury in this model.

In addition to the renal protective functions of IL-33, several recent studies also revealed the profibrotic role of IL-33 in the IRI and UUO models $[19,54,55]$. Liu et al. demonstrated that BRG1 (Brahma-related gene-1)-mediated IL-33 expression promotes profibrogenic responses in the endothelial and renal tubular cells and that the knockdown of BRG-1 in the endothelial cells mitigated the ischemia/reperfusion-induced renal injury and fibrosis in the mouse model [54]. Liang et al. demonstrated that treatment with exogenous IL-33 (0.5 $\mu \mathrm{g} /$ day for 2 weeks; i.p. injection) promoted IRI-induced renal fibrosis, whereas IL-33 neutralization by sST2 (100 $\mu \mathrm{g} /$ day for 2 weeks; i.p. injection) decreased the degree of kidney injury, extracellular matrix depositions, myeloid fibroblast accumulation, myofibroblast formation, and infiltration of T-cells and macrophages in the kidneys at day 14 post-IRI [53]. In this study, the contralateral kidney was removed at day 5 after unilateral IRI surgery to evaluate the renal function post-IRI [53].

UUO model has been extensively used to study the progression of renal fibrosis following kidney obstruction [42,70]. In the UUO model, the obstructed kidney is characterized by renal tubular dilation, loss of proximal tubular mass, infiltration of immune cells, and fibrosis. Upon obstructive kidney injury, the insults of mechanical stretch and increased intra-renal pressure may lead to progressive renal tubulointerstitial fibrosis if the obstruction is not resolved [42]. Our previous study reported that the deficiency of IL33 or IL1RL1 partially reversed the UUO-induced renal fibrosis [19]. Similarly, Li et al. demonstrated that UUO kidney exhibited upregulated expression levels of IL33 and IL1RL1. Exogenous IL-33 increased the macrophage infiltration and renal fibrosis with a concomitant increase in the AAMs [55]. Li et al. reported that exogenous IL-33 promotes kidney fibrosis via the effector function 
of AAMs in the UUO model [55]. Our previous study investigated the ST2+ immune cell profile in the kidney, which revealed that the myeloid cells are the major targets of IL-33 in the UUO-induced obstructed kidney [58]. However, the deletion of Il33 reduced the protein levels of type 2 cytokines in the urine isolated from the UUO kidney [58]. This suggested that the endogenous IL-33 contributes to the production of the type 2 cytokines in the UUO model. The differential roles of IL-33 in tissue fibrotic responses can be attributed to the different pathological conditions, tissue responses upon injury insults, and the analysis endpoints between IRI and UUO models. Additionally, the UUO model potentially exhibits both acute and chronic insults following irreversible kidney obstruction and is attributed to differential pathological outcomes between the IRI and UUO models.

\section{Potential Applications and Caveats of Therapeutic Targeting IL-33/ST2 Signaling}

In the last few decades, the loss-of-function approaches, such as gene knockout or specific immune cell depletion models, have been extensively used to investigate the biological function of IL-33/ST2 axis-mediated immunomodulatory response and its therapeutic potential. It is important to note that the interpretations of results from current studies using IL33 knockout (endogenous) or administration of IL-33 (exogenous) could vary depending on the use of different models. Additionally, IL-33 activity might be regulated by the endogenous antagonist, sST2. However, it is unclear whether the local tissue SST2 concentration is involved in the regulation of IL-33-mediated immune responses in vivo. The beneficial effects of IL33 deficiency and application of exogenous IL-33 or sST2 have been demonstrated by different groups. However, it is important to note that the experimental findings using exogenous IL-33 administration do not equally explain the endogenous function of IL-33 as IL-33 is endogenously expressed in various organs. The local concentration of mature IL-33 should be considered when interpreting the results from studies using exogenous IL-33 treatment.

IL-33 knockout mouse was used to analyze the loss-of-function of endogenous IL-33. It remains unclear whether the dual roles of the nuclear IL-33 or extracellular IL-33 via ST2-independent or ST2-dependent pathways contribute to differential outcomes under disease conditions, such as IRI. In the IL-33-deficient mice, both the nuclear and extracellular functions of IL-33 were abolished. Although the exact function of nuclear IL-33 is unclear, the nuclear IL-33 was reported to interact with nuclear factor (NF)- $\mathrm{KB}$ and inhibit NF- $\mathrm{kB}$-stimulated gene transcription [71]. The nuclear function and stability of IL-33 were regulated by the enzyme ubiquitin-specific protease 17 (USP17) through the deubiquitination of IL-33 at both the K48 and K63 sites [72]. The biological activity of IL-33 is rapidly inactivated in the extracellular environment by forming two disulfide bonds, which results in a conformational change and disruption of the ST2 binding site [73]. The release of IL-33 from the nucleus to the extracellular matrix was mediated by an ATP-dependent nuclear pore complex [74]. The chromatin binding of IL-33 was reported to be associated with the ST2 signaling in neutrophil extracellular traps (NET)-induced signaling [75]. However, the detailed molecular mechanisms involved in the regulation of IL-33 translocation in living cells are poorly understood. The nuclear expression of IL-33 was dispensable for its biological function in the human umbilical vein endothelial cells (HUVECs) [76]. In addition to the endothelial cells, other types of cells express nuclear IL-33 in the kidney, such as interstitial fibroblasts [19] and hyperplasic KRT-5+ urothelial cells [58]. The effect of IL33 deficiency on gene expression in these cells under healthy and disease conditions remains unknown.

Several groups have generated IL1RL1-deficient mice for the genetic deletion of the IL-33 receptor, which is encoded by the IL1RL1 gene. Sehnine et al. used the IL1RL1 knockout mice to demonstrate that streptozotocin (STZ)-induced hyperglycemic mice exhibited an increased urinary albumin excretion [77]. At $24 \mathrm{~h}$ post-IRI, the ST2 knockout mice exhibited markedly reduced plasma creatinine, blood urea nitrogen (BUN), and tubular injury. However, this protective effect was mitigated in the ST2-induced diabetes mellitus (DM) mice [77]. This suggested that the high glucose environment may impair the IL-33/ST2-mediated renal protective function. Several groups have generated ST2 knockout mice by knocking out the IL1RL1 gene. The IL1RL1 knockout in mice resulted in the deletion of both membrane (ST2L) and soluble (sST2) forms of ST2. However, the production 
of sST2 and the formation of sST2 concentration gradient, which is observed in the myocardium, in the kidney are unknown [78]. Additionally, the role of IL-33/ST2 signaling in non-immune cells is not well understood. Osmotic stress regulates the expression of IL1RL1 in the collecting duct cells. However, the type of transcript isoform that is altered is not known [79]. The comparative analysis of IL-33 and sST2 tissue levels, as well as the distribution of ST2-expressing cells (immune and non-immune cells), will aid in understanding the mechanistic control of IL-33/ST2 signaling within the tissue microenvironment. Moreover, the IL1RL1 knockout lines currently used lack both the ST2L and SST2 isoforms, which prevents the interpretation of the physiological regulation of IL-33/ST2 signaling by sST2. Future studies must focus on specifically targeting the ST2L or sST2 isoforms, which will improve our understanding of the IL-33/ST2 axis-mediated immune responses.

\section{Conclusions}

Recent evidence indicates that IL-33/ST2 signaling contributes to the pathogenesis of multiple diseases that are associated with kidney injury. Short-term exogenous IL-33 treatment at the early stage of disease onset could be beneficial, whereas long-term (high-dose) treatment may exacerbate the progression of renal fibrosis. The tissue-resident ILC2s and Tregs could be the first-line immune microenvironment modifiers in response to exogenous IL-33 treatment. Further studies are needed to elucidate the IL-33-mediated (or ILC2- and Tregs-mediated) immune microenvironment changes in the kidney for treating AKI. This review summarized the potential functions of endogenous IL-33and exogenous IL-33-mediated tissue responses in kidney tissues following acute injury (Figures 1 and 2).
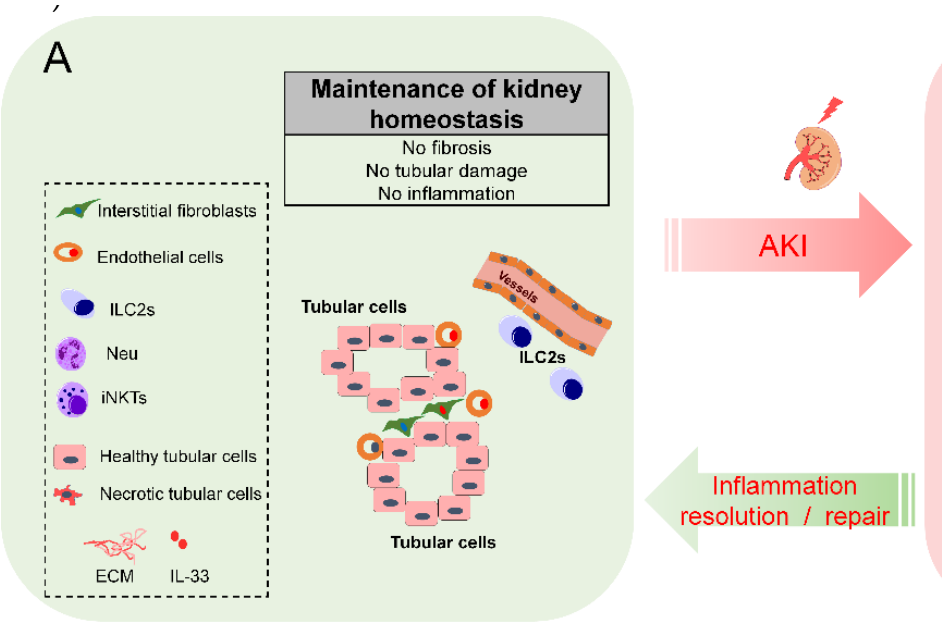

B
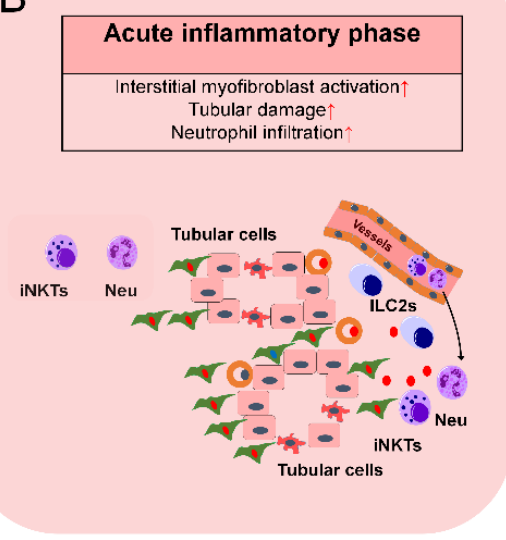

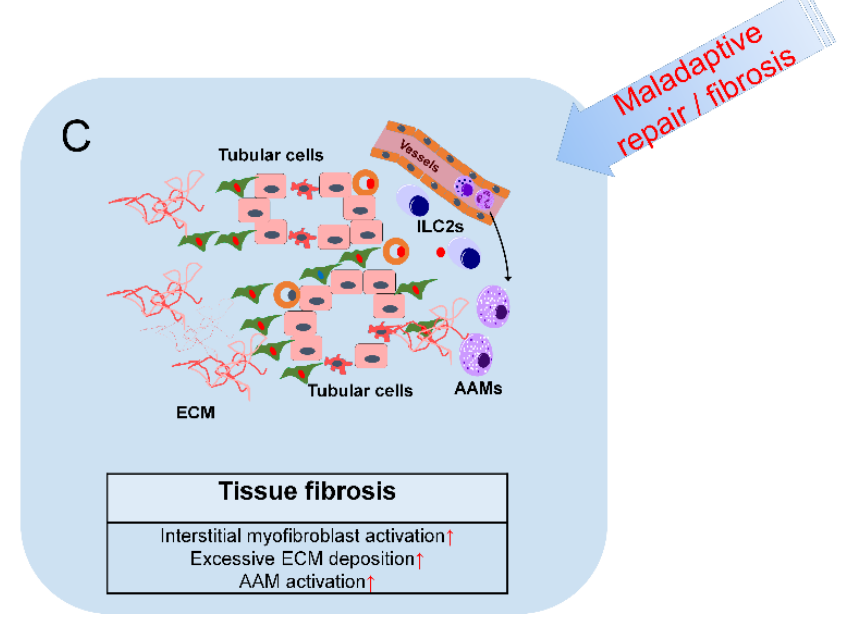

Figure 1. IL-33-mediated immunomodulatory networks in acute kidney injury. (A) IL-33 is expressed in the interstitial fibroblasts and endothelial cells in healthy kidney. (B) During the acute inflammatory 
phase of following kidney injury (0-24 h), IL-33 mediates the recruitment of immune cells, such as neutrophils and macrophages, and the amplification of inflammatory responses via iNKT cells. (C) During the recovery phase, IL-33 can mediate the activation of anti-inflammatory responses via ILC2s, alternatively activated macrophages (AAMs), and regulatory T-cells (Tregs). However, maladaptive repair or excessive interstitial myofibroblast activation may result in excessive extracellular matrix (ECM) deposition. Long-term treatment with high-dose exogenous IL-33 may promote tissue fibrosis if the analysis is performed at later stages of disease onset following kidney injury.

Collectively, IL-33 exhibits diverse immune regulatory functions during the various phases of different diseases. Endogenous IL-33, which is upregulated at early stages after tissue injury, functions as an acute-phase alarmin to amplify the innate inflammatory responses, whereas exogenous IL-33 (short-term, low-dose) can function as anti-inflammatory via activation of ILC2s, Tregs, and MDSCs. The immunomodulatory roles of IL-33 in tissue inflammation and repair in different renal injury models are not completely understood and require comprehensive investigation.

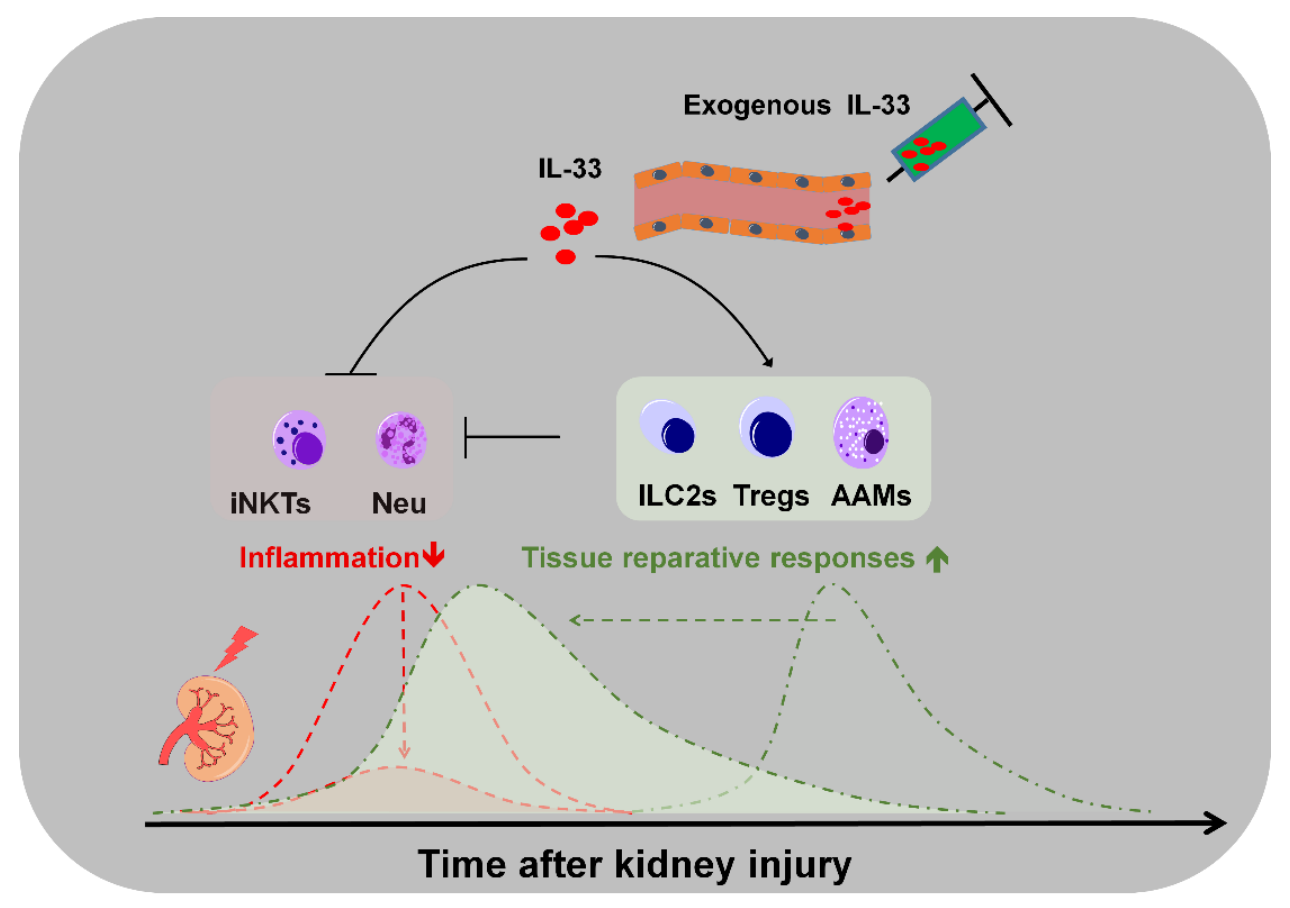

Figure 2. IL-33 treatment may promote tissue-reparative responses and inhibit inflammation in AKI. Treatment with exogenous IL-33 at different time points before or after kidney injury can mediate differential immune responses by targeting different immune cells. IL-33 treatment may skew the kidney ILC2s toward renal protective response. Additionally, IL-33 treatment following ischemia-reperfusion injury (IRI) could promote inflammation resolution and kidney repair potentially through ILC2and AAM-derived factors. The renal protective function of exogenous IL-33 is potentially mediated by AAMs in the absence of endogenous ILC2s.

In clinical settings, sepsis in critically ill patients is one of the major causes of AKI. IL-33 has been shown to promote bacteria clearance in a mouse model of sepsis [80]. However, it is not clear whether IL-33 treatment contributes to improved kidney function in the septic animals. Additionally, the balance between neutrophil- and eosinophil-mediated immune responses have attributed to the outcomes of ILC2-mediated protective effect against Staphylococcus aureus bacteremia-induced mortality [80]. Further investigation to determine blood neutrophils versus eosinophils ratio in patients with sepsis-associated AKI will help to decipher the contribution of the IL-33/ILC2 axis in the patient population. 
The tissue reparative responses and the process of tissue fibrosis are double-edged swords. The fine-tuning of tissue reparative process could result in less fibrotic scar formation and promote optimal tissue repair and clinical outcomes. Currently, an effective therapy for preventing acute kidney injury, other than supportive management, remains a largely unmet medical need. IL-33 may function as a crucial immunomodulator to mediate the balance between tissue repair and fibrosis responses and could be a potential therapeutic target for AKI. Although IL-33 has been shown to play a protective role in several AKI animal models, there are several limitations to the use of these AKI models in the study of inflammation and therapeutic targets. These limitations include the difference in species, immune responses, and susceptibility to AKI insults between humans and animal models [34]. For clinical applications, further studies are needed to understand the IL-33-mediated immune responses in humans. The optimization of the timing, dosages, and tissue specificity may be crucial for the development of IL-33-based therapeutics for treating various kidney diseases, such as AKI.

Author Contributions: Writing—original draft preparation, review, and editing, W.-Y.C., L.-C.L., Y.-H.W., J.-L.Y. and H.-T.T. All authors have read and agreed to the published version of the manuscript.

Funding: This research was funded by the Ministry of Science and Technology (MOST) of Taiwan (108-2628-B-182A-007- to W.-Y.C. and 108-2320-B-182A-002 -MY2 to H.-T.T.) and Chang Gung Medical Foundation (CMRPG8D0231-3, CMRPG8G0851-2, CMRPG8I0161-2, to W.-Y.C.; CMRPG8H1051, CMRPG8J1241 to H.-T.T.).

Conflicts of Interest: The authors declare no conflict of interest.

\section{Abbreviations}

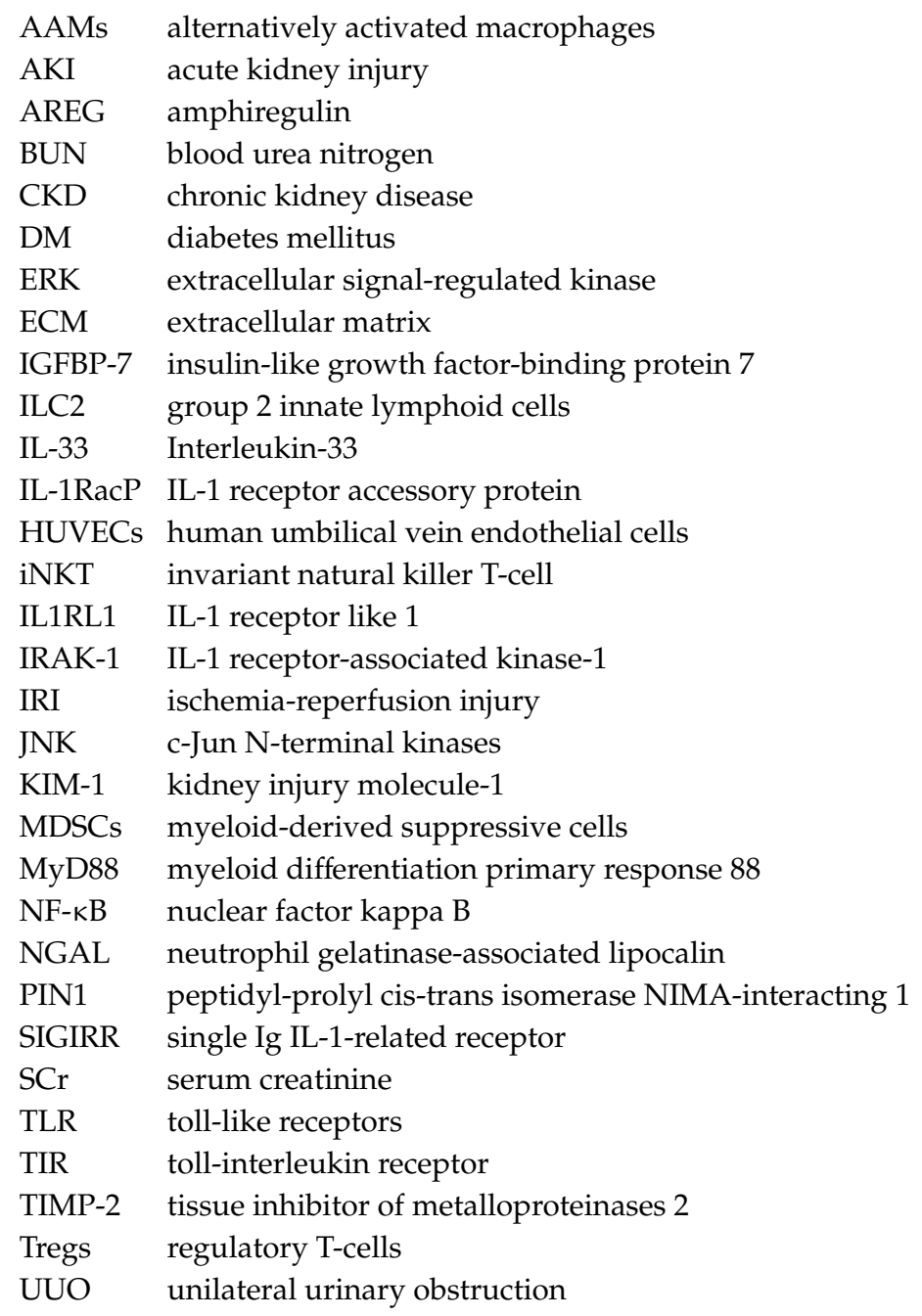




\section{References}

1. Liew, F.Y.; Girard, J.P.; Turnquist, H.R. Interleukin-33 in health and disease. Nat. Rev. Immunol. 2016, 16, 676-689. [CrossRef] [PubMed]

2. Liu, X.; Xiao, Y.; Pan, Y.; Li, H.; Zheng, S.G.; Su, W. The role of the IL-33/ST2 axis in autoimmune disorders: Friend or foe? Cytokine Growth Factor Rev. 2019. [CrossRef] [PubMed]

3. Cayrol, C.; Girard, J.P. IL-33: An alarmin cytokine with crucial roles in innate immunity, inflammation and allergy. Curr. Opin. Immunol. 2014, 31,31-37. [CrossRef] [PubMed]

4. Schmitz, J.; Owyang, A.; Oldham, E.; Song, Y.; Murphy, E.; McClanahan, T.K.; Zurawski, G.; Moshrefi, M.; Qin, J.; Li, X.; et al. IL-33, an interleukin-1-like cytokine that signals via the IL-1 receptor-related protein ST2 and induces T helper type 2-associated cytokines. Immunity 2005, 23, 479-490. [CrossRef] [PubMed]

5. Pichery, M.; Mirey, E.; Mercier, P.; Lefrancais, E.; Dujardin, A.; Ortega, N.; Girard, J.P. Endogenous IL-33 is highly expressed in mouse epithelial barrier tissues, lymphoid organs, brain, embryos, and inflamed tissues: In situ analysis using a novel Il-33-LacZ gene trap reporter strain. J. Immunol. 2012, 188, 3488-3495. [CrossRef] [PubMed]

6. Carriere, V.; Roussel, L.; Ortega, N.; Lacorre, D.A.; Americh, L.; Aguilar, L.; Bouche, G.; Girard, J.P. IL-33, the IL-1-like cytokine ligand for ST2 receptor, is a chromatin-associated nuclear factor in vivo. Proc. Natl. Acad. Sci. USA 2007, 104, 282-287. [CrossRef]

7. Talabot-Ayer, D.; Lamacchia, C.; Gabay, C.; Palmer, G. Interleukin-33 is biologically active independently of caspase-1 cleavage. J. Biol. Chem. 2009, 284, 19420-19426. [CrossRef]

8. Lefrancais, E.; Roga, S.; Gautier, V.; Gonzalez-de-Peredo, A.; Monsarrat, B.; Girard, J.P.; Cayrol, C. IL-33 is processed into mature bioactive forms by neutrophil elastase and cathepsin G. Proc. Natl. Acad. Sci. USA 2012, 109, 1673-1678. [CrossRef]

9. Lefrancais, E.; Duval, A.; Mirey, E.; Roga, S.; Espinosa, E.; Cayrol, C.; Girard, J.P. Central domain of IL-33 is cleaved by mast cell proteases for potent activation of group-2 innate lymphoid cells. Proc. Natl. Acad. Sci. USA 2014, 111, 15502-15507. [CrossRef]

10. Milovanovic, M.; Volarevic, V.; Radosavljevic, G.; Jovanovic, I.; Pejnovic, N.; Arsenijevic, N.; Lukic, M.L. IL-33/ST2 axis in inflammation and immunopathology. Immunol. Res. 2012, 52, 89-99. [CrossRef]

11. Martin, N.T.; Martin, M.U. Interleukin 33 is a guardian of barriers and a local alarmin. Nat. Immunol. 2016, 17, 122-131. [CrossRef] [PubMed]

12. Griesenauer, B.; Paczesny, S. The ST2/IL-33 Axis in Immune Cells during Inflammatory Diseases. Front. Immunol. 2017, 8, 475. [CrossRef] [PubMed]

13. Funakoshi-Tago, M.; Tago, K.; Hayakawa, M.; Tominaga, S.; Ohshio, T.; Sonoda, Y.; Kasahara, T. TRAF6 is a critical signal transducer in IL-33 signaling pathway. Cell. Signal. 2008, 20, 1679-1686. [CrossRef] [PubMed]

14. Molofsky, A.B.; Savage, A.K.; Locksley, R.M. Interleukin-33 in Tissue Homeostasis, Injury, and Inflammation. Immunity 2015, 42, 1005-1019. [CrossRef] [PubMed]

15. Nechama, M.; Kwon, J.; Wei, S.; Kyi, A.T.; Welner, R.S.; Ben-Dov, I.Z.; Arredouani, M.S.; Asara, J.M.; Chen, C.H.; Tsai, C.Y.; et al. The IL-33-PIN1-IRAK-M axis is critical for type 2 immunity in IL-33-induced allergic airway inflammation. Nat. Commun. 2018, 9, 1603. [CrossRef] [PubMed]

16. Bulek, K.; Swaidani, S.; Qin, J.; Lu, Y.; Gulen, M.F.; Herjan, T.; Min, B.; Kastelein, R.A.; Aronica, M.; Kosz-Vnenchak, M.; et al. The essential role of single Ig IL-1 receptor-related molecule/Toll IL-1R8 in regulation of Th2 immune response. J. Immunol. 2009, 182, 2601-2609. [CrossRef]

17. Cameron, G.J.M.; Jiang, S.H.; Loering, S.; Deshpande, A.V.; Hansbro, P.M.; Starkey, M.R. Emerging therapeutic potential of group 2 innate lymphoid cells in acute kidney injury. J. Pathol. 2019, 248, 9-15. [CrossRef]

18. Chen, W.Y.; Li, L.C.; Yang, J.L. Emerging Roles of IL-33/ST2 Axis in Renal Diseases. Int. J. Mol. Sci. 2017, 18, 783. [CrossRef]

19. Chen, W.Y.; Chang, Y.J.; Su, C.H.; Tsai, T.H.; Chen, S.D.; Hsing, C.H.; Yang, J.L. Upregulation of Interleukin-33 in obstructive renal injury. Biochem. Biophys. Res. Commun. 2016, 473, 1026-1032. [CrossRef]

20. Akcay, A.; Nguyen, Q.; He, Z.; Turkmen, K.; Won Lee, D.; Hernando, A.A.; Altmann, C.; Toker, A.; Pacic, A.; Ljubanovic, D.G.; et al. IL-33 exacerbates acute kidney injury. J. Am. Soc. Nephrol. 2011, 22, 2057-2067. [CrossRef] 
21. Martin-Sanchez, D.; Ruiz-Andres, O.; Poveda, J.; Carrasco, S.; Cannata-Ortiz, P.; Sanchez-Nino, M.D.; Ruiz Ortega, M.; Egido, J.; Linkermann, A.; Ortiz, A.; et al. Ferroptosis, but Not Necroptosis, Is Important in Nephrotoxic Folic Acid-Induced AKI. J. Am. Soc. Nephrol. 2017, 28, 218-229. [CrossRef] [PubMed]

22. Thierry, A.; Giraud, S.; Robin, A.; Barra, A.; Bridoux, F.; Ameteau, V.; Hauet, T.; Girard, J.P.; Touchard, G.; Gombert, J.M.; et al. The alarmin concept applied to human renal transplantation: Evidence for a differential implication of HMGB1 and IL-33. PLoS ONE 2014, 9, e88742. [CrossRef] [PubMed]

23. Rewa, O.; Bagshaw, S.M. Acute kidney injury-epidemiology, outcomes and economics. Nat. Rev. Nephrol. 2014, 10, 193-207. [CrossRef] [PubMed]

24. Go, A.S.; Chertow, G.M.; Fan, D.; McCulloch, C.E.; Hsu, C.Y. Chronic kidney disease and the risks of death, cardiovascular events, and hospitalization. N. Engl. J. Med. 2004, 351, 1296-1305. [CrossRef]

25. Kellum, J.A.; Lameire, N. The definition of acute kidney injury. Lancet 2018, 391, 202-203. [CrossRef]

26. Dennen, P.; Parikh, C.R. Biomarkers of acute kidney injury: Can we replace serum creatinine? Clin. Nephrol. 2007, 68, 269-278. [CrossRef]

27. Aregger, F.; Uehlinger, D.E.; Witowski, J.; Brunisholz, R.A.; Hunziker, P.; Frey, F.J.; Jorres, A. Identification of IGFBP-7 by urinary proteomics as a novel prognostic marker in early acute kidney injury. Kidney Int. 2014, 85, 909-919. [CrossRef]

28. Huen, S.C.; Parikh, C.R. Molecular phenotyping of clinical AKI with novel urinary biomarkers. Am. J. Physiol. Renal Physiol. 2015, 309, F406-F413. [CrossRef]

29. Zhang, W.R.; Parikh, C.R. Biomarkers of Acute and Chronic Kidney Disease. Annu. Rev. Physiol. 2019, 81, $309-333$. [CrossRef]

30. Takahashi, S.; Nakasatomi, M.; Takei, Y.; Ikeuchi, H.; Sakairi, T.; Kaneko, Y.; Hiromura, K.; Nojima, Y.; Maeshima, A. Identification of Urinary Activin A as a Novel Biomarker Reflecting the Severity of Acute Kidney Injury. Sci. Rep. 2018, 8, 5176. [CrossRef]

31. Vijayan, A.; Faubel, S.; Askenazi, D.J.; Cerda, J.; Fissell, W.H.; Heung, M.; Humphreys, B.D.; Koyner, J.L.; Liu, K.D.; Mour, G.; et al. Clinical Use of the Urine Biomarker [TIMP-2] x [IGFBP7] for Acute Kidney Injury Risk Assessment. Am. J. Kidney Dis. 2016, 68, 19-28. [CrossRef]

32. Ronco, C.; Bellomo, R.; Kellum, J.A. Acute kidney injury. Lancet 2019, 394, 1949-1964. [CrossRef]

33. Moore, P.K.; Hsu, R.K.; Liu, K.D. Management of Acute Kidney Injury: Core Curriculum 2018. Am. J. Kidney Dis. 2018, 72, 136-148. [CrossRef] [PubMed]

34. Rabb, H.; Griffin, M.D.; McKay, D.B.; Swaminathan, S.; Pickkers, P.; Rosner, M.H.; Kellum, J.A.; Ronco, C.; Acute Dialysis Quality Initiative Consensus, X.W.G. Inflammation in AKI: Current Understanding, Key Questions, and Knowledge Gaps. J. Am. Soc. Nephrol. 2016, 27, 371-379. [CrossRef] [PubMed]

35. Lee, S.A.; Noel, S.; Sadasivam, M.; Hamad, A.R.A.; Rabb, H. Role of Immune Cells in Acute Kidney Injury and Repair. Nephron 2017, 137, 282-286. [CrossRef] [PubMed]

36. Zhou, D.; Fu, H.; Liu, S.; Zhang, L.; Xiao, L.; Bastacky, S.I.; Liu, Y. Early activation of fibroblasts is required for kidney repair and regeneration after injury. FASEB J. 2019, 33, 12576-12587. [CrossRef] [PubMed]

37. Ferenbach, D.A.; Bonventre, J.V. Mechanisms of maladaptive repair after AKI leading to accelerated kidney ageing and CKD. Nat. Rev. Nephrol. 2015, 11, 264-276. [CrossRef]

38. Cao, Q.; Harris, D.C.; Wang, Y. Macrophages in kidney injury, inflammation, and fibrosis. Physiology (Bethesda) 2015, 30, 183-194. [CrossRef]

39. Kellum, J.A.; Sileanu, F.E.; Bihorac, A.; Hoste, E.A.; Chawla, L.S. Recovery after Acute Kidney Injury. Am. J. Respir. Crit. Care Med. 2017, 195, 784-791. [CrossRef]

40. Ortiz, A.; Sanchez-Nino, M.D.; Izquierdo, M.C.; Martin-Cleary, C.; Garcia-Bermejo, L.; Moreno, J.A.; Ruiz-Ortega, M.; Draibe, J.; Cruzado, J.M.; Garcia-Gonzalez, M.A.; et al. Translational value of animal models of kidney failure. Eur. J. Pharmacol. 2015, 759, 205-220. [CrossRef]

41. Wei, Q.; Dong, Z. Mouse model of ischemic acute kidney injury: Technical notes and tricks. Am. J. Physiol. Renal Physiol. 2012, 303, F1487-F1494. [CrossRef] [PubMed]

42. Martinez-Klimova, E.; Aparicio-Trejo, O.E.; Tapia, E.; Pedraza-Chaverri, J. Unilateral Ureteral Obstruction as a Model to Investigate Fibrosis-Attenuating Treatments. Biomolecules 2019, 9, 141. [CrossRef] [PubMed]

43. Jang, H.R.; Rabb, H. Immune cells in experimental acute kidney injury. Nat. Rev. Nephrol. 2015, 11, 88-101. [CrossRef] [PubMed]

44. Meng, X.M.; Nikolic-Paterson, D.J.; Lan, H.Y. Inflammatory processes in renal fibrosis. Nat. Rev. Nephrol. 2014, 10, 493-503. [CrossRef] 
45. Braun, H.; Afonina, I.S.; Mueller, C.; Beyaert, R. Dichotomous function of IL-33 in health and disease: From biology to clinical implications. Biochem. Pharmacol. 2018, 148, 238-252. [CrossRef]

46. Afferni, C.; Buccione, C.; Andreone, S.; Galdiero, M.R.; Varricchi, G.; Marone, G.; Mattei, F.; Schiavoni, G. The Pleiotropic Immunomodulatory Functions of IL-33 and Its Implications in Tumor Immunity. Front. Immunol. 2018, 9, 2601. [CrossRef]

47. Zhang, C.; Li, L.; Feng, K.; Fan, D.; Xue, W.; Lu, J. ‘Repair’’ Treg Cells in Tissue Injury. Cell Physiol. Biochem. 2017, 43, 2155-2169. [CrossRef]

48. Riedel, J.H.; Becker, M.; Kopp, K.; Duster, M.; Brix, S.R.; Meyer-Schwesinger, C.; Kluth, L.A.; Gnirck, A.C.; Attar, M.; Krohn, S.; et al. IL-33-Mediated Expansion of Type 2 Innate Lymphoid Cells Protects from Progressive Glomerulosclerosis. J. Am. Soc. Nephrol. 2017, 28, 2068-2080. [CrossRef]

49. Cao, Q.; Wang, Y.; Niu, Z.; Wang, C.; Wang, R.; Zhang, Z.; Chen, T.; Wang, X.M.; Li, Q.; Lee, V.W.S.; et al. Potentiating Tissue-Resident Type 2 Innate Lymphoid Cells by IL-33 to Prevent Renal Ischemia-Reperfusion Injury. J. Am. Soc. Nephrol. 2018, 29, 961-976. [CrossRef]

50. Sabapathy, V.; Cheru, N.T.; Corey, R.; Mohammad, S.; Sharma, R. A Novel Hybrid Cytokine IL233 Mediates regeneration following Doxorubicin-Induced Nephrotoxic Injury. Sci. Rep. 2019, 9, 3215. [CrossRef]

51. Stremska, M.E.; Jose, S.; Sabapathy, V.; Huang, L.; Bajwa, A.; Kinsey, G.R.; Sharma, P.R.; Mohammad, S.; Rosin, D.L.; Okusa, M.D.; et al. IL233, A Novel IL-2 and IL-33 Hybrid Cytokine, Ameliorates Renal Injury. J. Am. Soc. Nephrol. 2017, 28, 2681-2693. [CrossRef] [PubMed]

52. Zaiss, D.M.W.; Gause, W.C.; Osborne, L.C.; Artis, D. Emerging functions of amphiregulin in orchestrating immunity, inflammation, and tissue repair. Immunity 2015, 42, 216-226. [CrossRef] [PubMed]

53. Liang, H.; Xu, F.; Wen, X.J.; Liu, H.Z.; Wang, H.B.; Zhong, J.Y.; Yang, C.X.; Zhang, B. Interleukin-33 signaling contributes to renal fibrosis following ischemia reperfusion. Eur. J. Pharmacol. 2017, 812, 18-27. [CrossRef] [PubMed]

54. Liu, L.; Mao, L.; Wu, X.; Wu, T.; Liu, W.; Yang, Y.; Zhang, T.; Xu, Y. BRG1 regulates endothelial-derived IL-33 to promote ischemia-reperfusion induced renal injury and fibrosis in mice. Biochim. Biophys. Acta Mol. Basis Dis. 2019, 1865, 2551-2561. [CrossRef]

55. Li, Y.; Liu, J.; Yu, T.; Yan, B.; Li, H. Interleukin33 promotes obstructive renal injury via macrophages. Mol. Med. Rep. 2019, 20, 1353-1362. [CrossRef]

56. Park, G.H.; Shinn, H.K.; Kang, J.H.; Na, W.J.; Kim, Y.H.; Park, C.S. Anti-interleukin-33 Reduces Ovalbumin-Induced Nephrotoxicity and Expression of Kidney Injury Molecule-1. Int. Neurourol. J. 2016, 20, 114-121. [CrossRef]

57. Tait Wojno, E.D.; Beamer, C.A. Isolation and Identification of Innate Lymphoid Cells (ILCs) for Immunotoxicity Testing. Methods Mol. Biol. 2018, 1803, 353-370. [CrossRef]

58. Chen, W.Y.; Yang, J.L.; Wu, Y.H.; Li, L.C.; Li, R.F.; Chang, Y.T.; Dai, L.H.; Wang, W.C.; Chang, Y.J. IL-33/ST2 axis mediates hyperplasia of intrarenal urothelium in obstructive renal injury. Exp. Mol. Med. 2018, 50, 36. [CrossRef]

59. Cameron, G.J.M.; Cautivo, K.M.; Loering, S.; Jiang, S.H.; Deshpande, A.V.; Foster, P.S.; McKenzie, A.N.J.; Molofsky, A.B.; Hansbro, P.M.; Starkey, M.R. Group 2 Innate Lymphoid Cells Are Redundant in Experimental Renal Ischemia-Reperfusion Injury. Front. Immunol. 2019, 10, 826. [CrossRef]

60. Vely, F.; Barlogis, V.; Vallentin, B.; Neven, B.; Piperoglou, C.; Ebbo, M.; Perchet, T.; Petit, M.; Yessaad, N.; Touzot, F.; et al. Evidence of innate lymphoid cell redundancy in humans. Nat. Immunol. 2016, 17, 1291-1299. [CrossRef]

61. Stier, M.T.; Zhang, J.; Goleniewska, K.; Cephus, J.Y.; Rusznak, M.; Wu, L.; Van Kaer, L.; Zhou, B.; Newcomb, D.C.; Peebles, R.S., Jr. IL-33 promotes the egress of group 2 innate lymphoid cells from the bone marrow. J. Exp. Med. 2018, 215, 263-281. [CrossRef] [PubMed]

62. Ferhat, M.; Robin, A.; Giraud, S.; Sena, S.; Goujon, J.M.; Touchard, G.; Hauet, T.; Girard, J.P.; Gombert, J.M.; Herbelin, A.; et al. Endogenous IL-33 Contributes to Kidney Ischemia-Reperfusion Injury as an Alarmin. J. Am. Soc. Nephrol. 2018, 29, 1272-1288. [CrossRef] [PubMed]

63. Hardman, C.; Ogg, G. Interleukin-33, friend and foe in type-2 immune responses. Curr. Opin. Immunol. 2016, 42, 16-24. [CrossRef] [PubMed]

64. Huang, Q.; Niu, Z.; Tan, J.; Yang, J.; Liu, Y.; Ma, H.; Lee, V.W.; Sun, S.; Song, X.; Guo, M.; et al. IL-25 Elicits Innate Lymphoid Cells and Multipotent Progenitor Type 2 Cells That Reduce Renal Ischemic/Reperfusion Injury. J. Am. Soc. Nephrol. 2015, 26, 2199-2211. [CrossRef] [PubMed] 
65. Stremska, M.E.; Dai, C.; Venkatadri, R.; Wang, H.; Sabapathy, V.; Kumar, G.; Jose, S.; Mohammad, S.; Sung, S.J.; Fu, S.M.; et al. IL233, an IL-2-IL-33 hybrid cytokine induces prolonged remission of mouse lupus nephritis by targeting Treg cells as a single therapeutic agent. J. Autoimmun. 2019, 102, 133-141. [CrossRef] [PubMed]

66. Sabapathy, V.; Stremska, M.E.; Mohammad, S.; Corey, R.L.; Sharma, P.R.; Sharma, R. Novel Immunomodulatory Cytokine Regulates Inflammation, Diabetes, and Obesity to Protect From Diabetic Nephropathy. Front. Pharmacol. 2019, 10, 572. [CrossRef]

67. Nascimento, D.C.; Melo, P.H.; Pineros, A.R.; Ferreira, R.G.; Colon, D.F.; Donate, P.B.; Castanheira, F.V.; Gozzi, A.; Czaikoski, P.G.; Niedbala, W.; et al. IL-33 contributes to sepsis-induced long-term immunosuppression by expanding the regulatory T cell population. Nat. Commun. 2017, 8, 14919. [CrossRef]

68. Moussion, C.; Ortega, N.; Girard, J.P. The IL-1-like cytokine IL-33 is constitutively expressed in the nucleus of endothelial cells and epithelial cells in vivo: A novel 'alarmin'? PLoS ONE 2008, 3, e3331. [CrossRef]

69. Ravichandran, K.; Holditch, S.; Brown, C.N.; Wang, Q.; Ozkok, A.; Weiser-Evans, M.C.; Nemenoff, R.; Miyazaki, M.; Thiessen-Philbrook, H.; Parikh, C.R.; et al. IL-33 deficiency slows cancer growth but does not protect against cisplatin-induced AKI in mice with cancer. Am. J. Physiol. Renal Physiol. 2018, 314, F356-F366. [CrossRef]

70. Chevalier, R.L.; Forbes, M.S.; Thornhill, B.A. Ureteral obstruction as a model of renal interstitial fibrosis and obstructive nephropathy. Kidney Int. 2009, 75, 1145-1152. [CrossRef]

71. Ali, S.; Mohs, A.; Thomas, M.; Klare, J.; Ross, R.; Schmitz, M.L.; Martin, M.U. The dual function cytokine IL-33 interacts with the transcription factor NF-kappaB to dampen NF-kappaB-stimulated gene transcription. J. Immunol. 2011, 187, 1609-1616. [CrossRef] [PubMed]

72. Ni, Y.; Tao, L.; Chen, C.; Song, H.; Li, Z.; Gao, Y.; Nie, J.; Piccioni, M.; Shi, G.; Li, B. The Deubiquitinase USP17 Regulates the Stability and Nuclear Function of IL-33. Int. J. Mol. Sci. 2015, 16, 27956-27966. [CrossRef] [PubMed]

73. Cohen, E.S.; Scott, I.C.; Majithiya, J.B.; Rapley, L.; Kemp, B.P.; England, E.; Rees, D.G.; Overed-Sayer, C.L.; Woods, J.; Bond, N.J.; et al. Oxidation of the alarmin IL-33 regulates ST2-dependent inflammation. Nat. Commun. 2015, 6, 8327. [CrossRef] [PubMed]

74. Kakkar, R.; Hei, H.; Dobner, S.; Lee, R.T. Interleukin 33 as a mechanically responsive cytokine secreted by living cells. J. Biol. Chem. 2012, 287, 6941-6948. [CrossRef] [PubMed]

75. Travers, J.; Rochman, M.; Miracle, C.E.; Habel, J.E.; Brusilovsky, M.; Caldwell, J.M.; Rymer, J.K.; Rothenberg, M.E. Chromatin regulates IL-33 release and extracellular cytokine activity. Nat. Commun. 2018, 9, 3244. [CrossRef] [PubMed]

76. Gautier, V.; Cayrol, C.; Farache, D.; Roga, S.; Monsarrat, B.; Burlet-Schiltz, O.; Gonzalez de Peredo, A.; Girard, J.P. Extracellular IL-33 cytokine, but not endogenous nuclear IL-33, regulates protein expression in endothelial cells. Sci. Rep. 2016, 6, 34255. [CrossRef]

77. Sehnine, M.; Ferhat, M.; Sena, S.; Gombert, J.M.; Goujon, J.M.; Thierry, A.; Touchard, G.; Hauet, T.; Herbelin, A.; Hadjadj, S. IL-33 receptor ST2 deficiency attenuates renal ischaemia-reperfusion injury in euglycaemic, but not streptozotocin-induced hyperglycaemic mice. Diabetes Metab. 2018, 44, 55-60. [CrossRef]

78. Chen, W.Y.; Hong, J.; Gannon, J.; Kakkar, R.; Lee, R.T. Myocardial pressure overload induces systemic inflammation through endothelial cell IL-33. Proc. Natl. Acad. Sci. USA 2015, 112, 7249-7254. [CrossRef]

79. Schulze Blasum, B.; Schroter, R.; Neugebauer, U.; Hofschroer, V.; Pavenstadt, H.; Ciarimboli, G.; Schlatter, E.; Edemir, B. The kidney-specific expression of genes can be modulated by the extracellular osmolality. FASEB J. 2016, 30, 3588-3597. [CrossRef]

80. Krishack, P.A.; Louviere, T.J.; Decker, T.S.; Kuzel, T.G.; Greenberg, J.A.; Camacho, D.F.; Hrusch, C.L.; Sperling, A.I.; Verhoef, P.A. Protection against Staphylococcus aureus bacteremia-induced mortality depends on ILC2s and eosinophils. JCI Insight 2019, 4. [CrossRef]

(C) 2020 by the authors. Licensee MDPI, Basel, Switzerland. This article is an open access article distributed under the terms and conditions of the Creative Commons Attribution (CC BY) license (http://creativecommons.org/licenses/by/4.0/). 